\title{
12 Implications of East Asia electricity market integration on Southeast Asian economies and $\mathrm{CO}_{2}$ emissions
}

\author{
Budy P. Resosudarmo and Yuventus Effendi
}

\section{Introduction}

In recent decades, there have been significant increases in electricity consumption around the world, including in the Southeast Asian region. In general, developing countries such as Vietnam and Indonesia had a remarkable increase in electricity consumption per capita from 2000 to 2015. Thus, trends indicate that in the next few years, electricity consumption would continue increasing in the Southeast Asian region. These increasing demands for electricity have been driven by the ongoing development of Southeast Asian economies, in particular, industrialization, access to electricity, and increasing household income (International Energy Agency, 2018).

Industrialization has been an important driver of electricity consumption as most industrial sectors are electricity intensive. In many countries, the industrial sector has been the largest electricity consumer of electricity. In 2010, for example, the global industrial sector accounted for approximately $74 \%$ of the total electricity consumption in that year (Wu et al., 2013). Increased access to electricity is another factor affecting the increasing electricity consumption. The number of people gaining access to electricity around the world has increased significantly since the mid-2000s, including in Southeast Asia. On average, approximately 50 million people every year had access to electricity for the first time between 2010 and 2017 (International Energy Agency, 2018). The third important factor is that as household incomes increase, their electricity demands increase as well. This is because of owning more household electric appliances, such as air conditioning and water heater appliances (Wolfram et al., 2012). Therefore, since the early 2000s, energy/electricity security has been an important issue in Southeast Asian countries (Nurdianto and Resosudarmo, 2016).

At the same time, $\mathrm{CO}_{2}$ emissions have also become a concern among Southeast Asian countries. Figure 12.1 shows that Southeast Asia has been among the top $\mathrm{CO}_{2}$ emitters globally. $\mathrm{CO}_{2}$ emissions from Southeast Asian countries are still among the largest, even if only emissions from fuel combustion activities are taken into consideration. The electricity sector is among the largest contributors to $\mathrm{CO}_{2}$ emissions from fuel combustion 


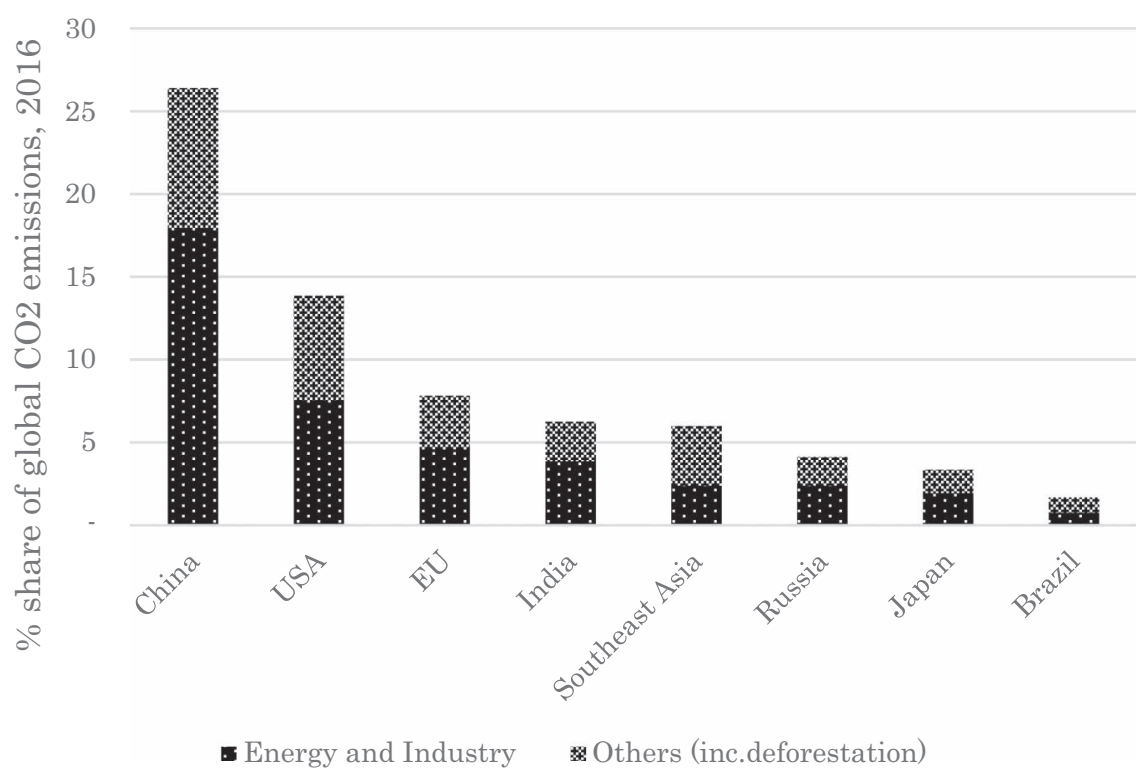

Figure 12.1 Top global $\mathrm{CO}_{2}$ emitters.

Note: USA = United States of America; EU = European Union.

Source: World Resources Institute (2020).

activities. To improve electricity security as well as manage $\mathrm{CO}_{2}$ emissions in the near future has been the topic of discussion in the region (Resosudarmo et al., 2021).

In order to improve electricity security and reduce $\mathrm{CO}_{2}$ emissions in Southeast Asia, two broad ideas can be considered. First, more investments in renewable electric power plants would certainly mitigate $\mathrm{CO}_{2}$ emissions. However, it is not yet clear whether it will significantly improve electricity security, efficient use of electricity, and economic development in the region. Second, regional electricity market integration is expected to improve electricity security. Countries either with surplus or capable of producing cheaper electricity would be able to supply neighboring countries in need. New investments on power plants in one country should, in theory, benefit other countries in the region as long as these countries are inter-connected. Hence, investments in the electricity sector would be more efficient. However, whether regional electricity market integration would lower the region's $\mathrm{CO}_{2}$ emissions and economic development is an empirical question. In other words, what would the overall impact of economic activities and $\mathrm{CO}_{2}$ emission leakage and relocation due to this regional electricity market integration on the region's $\mathrm{CO}_{2}$ emissions and economic development.

Although studies on the impact of investments on renewable electric power plants on the economy have been available (Denholm et al., 2012; 
Barbosa et al., 2017; Lilliestam et al., 2018), there is much less literature on the impacts of regional electricity market integration on the economy and the environment. Dahlke (2020) assesses the impacts of integrating energy market on energy prices and emissions in the Western US, and Newbery et al. (2016) analyze the impact of electricity market integration on the efficiency of the electricity trading system in European.

This chapter is different from the aforementioned studies, as it analyzes the impact of regional electricity market integration on both the economy and $\mathrm{CO}_{2}$ emissions. This chapter uses the concept of East Asia electricity market integration and the regional electricity market integration and examines the impact of this integration on macroeconomic indicators, such as gross domestic product (GDP), sectoral outputs, and factor incomes; socioeconomic indicators, such as poverty incidence and income distribution; and $\mathrm{CO}_{2}$ emissions in each Southeast Asia country.

To achieve the objective, this chapter develops an inter-regional social accounting matrix for East Asia (IRSAM-East Asia). It then derives an interregional constrained fixed price multiplier method to be able to analyze the impact of electricity market integration on the economy (Resosudarmo and Thorbecke, 1996; Hartono and Resosudarmo, 2008). To simulate the impact of economic changes on household incomes, household income microsimulation models for each Southeast Asian country are then constructed and utilized. Finally, sectoral $\mathrm{CO}_{2}$ emission models are used to simulate impact of these economic changes on the level of emissions from Southeast Asian countries.

\section{Regional electricity market integration}

Regional electricity (or energy) market integrations, although not many, have been available throughout the world. An example is the Nord Pool, a trading electricity power market institution - initially - among the Nordic countries (Norway, Sweden, Finland, and Denmark) ${ }^{1}$ and the Trilateral Market Coupling, a trading electricity power market institution - initiallyamong several Western Europe countries (France, Belgium, the Netherlands, Germany, and Luxemburg; Glachant, 2010). Since the establishment of these two electricity market integration institutions, members have been increasing.

The discussion on the possibilities to integrate electricity markets in East Asia region has been ongoing for a while. The first step toward this integration was an energy agreement between Thailand and the Lao PDR in the early 1970s. In 1981, Southeast Asian countries, which are members of the Association of Southeast Asian Nations (ASEAN), ${ }^{2}$ agreed to establish an ASEAN Power Utility Authority, followed by having an ASEAN Energy Cooperation Agreement in 1986 (Shi and Kimura, 2010). Additionally, the progress in establishing East Asia electricity market integration has been relatively slow (Wu et al., 2013). Nevertheless, in 2005, during the East Asia 
Summit, East Asian countries and Australia and New Zealand signed an initiative for Energy Market Integration (EMI). At almost the same time, ASEAN member countries attempted to establish a single market community within ASEAN members, similar to the European Union, including energy market (Wu et al., 2013; Nurdianto and Resosudarmo, 2016). Although there is no clear progress on the integrated energy market including the electricity market in East Asia until the writing of this chapter, several researchers are still optimistic that this integration would be happening in the next several decades (ERIA, 2014); their perspective is supported by incremental electricity integrations that keep taking place. For example, in 2019, Vietnam integrated its electricity system with those of Laos and Thailand. Discussions are underway on the possibility that Australia could export its green electricity in the near future (Garnaut, 2019). Therefore, this chapter focuses on the electricity market integration issue in the East Asian region as defined during the 2005 East Asia Summit, which covers not only Southeast Asian countries, China, Japan, and South Korea but also Australia and India.

\section{Simulation scenarios}

There are three main simulations in this chapter. The first simulation (SIM1) assumes that there is an increase in the output of the electricity sector in China by $10 \% .{ }^{3}$ The second simulation (SIM2) assumes an increase in the electricity output occurred in Indonesia by $10 \%$. The last main simulation (SIM3) is assuming a $10 \%$ increase in the output of Vietnamese electricity sector. $^{4}$

For each of these main simulations, this chapter considers three distinct situations. The first situation is the Business as Usual (BAU) situation in which there is no electricity market integration in East Asia (SIT1). This first situation mimics the current condition of the electricity market in East Asia, in which there is almost no connectivity between countries in East Asia. Thus, any increase in the electricity demand is fully fulfilled by the country itself.

The second situation (SIT2) is one where there is a fully integrated electricity market in East Asia that covers ASEAN member countries, Australia, China, Japan, India, and South Korea (also called as the East Asia electricity market integration). In this situation, it is assumed that any increase in electricity demand in a particular country is supplied by the country's domestic electricity production as well as electricity from other countries in East Asia. The electricity supplies from other countries would be through the inter-connected electricity transmission network across countries in East Asia. The contribution of each country as an electricity supplier is proportional to the electricity output of a particular country to total electricity output in the East Asia region. This second situation represents the aim of East Asia Energy Market Integration, which allows a fully integrated energy 
market among Southeast Asian countries, China, India, Japan, South Korea, and Australia.

The third situation (SIT3) is one where a fully integrated electricity market is only among Southeast Asian countries (i.e., the Southeast Asia electricity market integration). In this situation, any increase in a particular country is assumed to be supplied by the country's domestic electricity production and six Southeast Asian countries, namely, Indonesia, Malaysia, Thailand, the Philippines, Singapore, and Vietnam, and other ASEAN countries (as a group). This situation aims to capture the fact that Southeast Asian countries have been pushing to establish the ASEAN Economic Community, where an integrated energy market among ASEAN countries is one of their main targets (Nurdianto and Resosudarmo, 2016). ${ }^{5}$

Simulation results are presented in terms of relative to the outcomes under the SIT1. Any change in an indicator implies whether an integration in the electricity market in East Asia (SIT2), or only in Southeast Asia (SIT3), leads to better or worse off results compared to without any electricity market integration. In other words, the results presented in this chapter can be seen as the impacts of an integrated electricity market in East Asia (SIT2), or only in Southeast Asia region (SIT3).

\section{Methodology}

The first methodology utilized in this chapter is the inter-regional constrained fixed price multiplier method (Resosudarmo and Thorbecke, 1996, 1998). ${ }^{6}$ This method can simulate a situation such that an increase in output (an electricity sector in this chapter) is supplied by domestic production or import. The method is as follows.

Figure 12.2 describes two regions (Region 1 and Region 2) inter-regional Social Accounting Matrix (IRSAM). Each region consists of production activities, factor inputs, and institutions such as households. Outputs of some

\begin{tabular}{|c|c|c|c|c|c|}
\hline & \multicolumn{2}{|c|}{ Region 1} & Region 2 & ROW & TOTAL \\
\hline \multirow[t]{2}{*}{ Region 1} & $A_{C}^{11}$ & $R^{11}$ & $R^{12}$ & $X_{C}^{1}$ & $Y_{C}^{1}$ \\
\hline & $Q^{11}$ & $A_{N C}^{11}$ & $A_{N C}^{12}$ & $X_{N C}^{1}$ & $Y_{N C}^{1}$ \\
\hline Region 2 & $Q^{21}$ & $A_{N C}^{21}$ & $A_{N C}^{22}$ & $X_{N C}^{2}$ & $Y_{N C}^{2}$ \\
\hline ROW & \multicolumn{2}{|c|}{$l^{1}$} & $l^{2}$ & $t$ & $Y_{E}$ \\
\hline TOTAL & $\left(Y_{C}^{1}{ }^{\prime}\right.$ & $Y_{N C}^{1}{ }^{\prime}$ & $Y_{N C}^{2}{ }^{\prime}$ & $Y_{E}{ }^{\prime}$ & \\
\hline
\end{tabular}

Figure 12.2 Structure of IRSAM with constrained sector. 
productions in Region 1 are constrained $\left(Y_{C}^{1}\right)$ and others are unconstrained $\left(Y_{N C}^{1}\right.$ and $\left.Y_{N C}^{2}\right)$. The constrained sector in this chapter is the electricity sector, whereas other sectors are defined as unconstrained sectors. Also, there are exogenous accounts such as government, savings, and taxes, which are included in the rest of the world (ROW) column and row accordingly.

Terms $A_{C}^{11}, A_{N C}^{11}, R^{11}$, and $Q^{11}$ are matrices of expenditures among sectors within Region $1 ; A_{C}^{11}$ is among constrained sectors (electricity sectors in this chapter), $A_{N C}^{11}$ is among non-constrained sectors, $R^{11}$ is from nonconstrained sectors to constrained sectors, and $Q^{11}$ is from constrained sectors to non-constrained sectors. The term $A_{N C}^{22}$ is a matrix of expenditures among sectors within Region 2. The terms $A_{N C}^{12}$ and $R^{12}$ are matrices of expenditures from sectors in Region 2 to sectors in Region 1. However, $Q^{21}$ and $A_{N C}^{21}$ are matrices of expenditures from Region 1 to those in Region 2. The terms $l^{1}$ and $l^{2}$ are leakages to the ROW, while $X_{C}^{1}, X_{N C}^{1}$, and $X_{N C}^{2}$ are vectors of injection from the ROW. Finally, $t$ is a vector of exogenous not related to Region 1 nor to Region 2.

Figure 12.2 can be expressed mathematically as in equation (12-1).

$$
d\left[\begin{array}{c}
Y_{C}^{1} \\
Y_{N C}^{1} \\
Y_{N C}^{2}
\end{array}\right]=\left[\begin{array}{lll}
A_{C}^{11} & R^{11} & R^{12} \\
Q^{11} & A_{N C}^{11} & A_{N C}^{12} \\
Q^{21} & A_{N C}^{21} & A_{N C}^{22}
\end{array}\right] d\left[\begin{array}{c}
Y_{C}^{1} \\
Y_{N C}^{1} \\
Y_{N C}^{2}
\end{array}\right]+d\left[\begin{array}{c}
X_{C}^{1} \\
X_{N C}^{1} \\
X_{N C}^{2}
\end{array}\right]
$$

The matrices in equation (12-1) can be rearranged, following Hartono and Resosudarmo (2008) and Resosudarmo and Thorbecke (1996), and elaborated to depict the relationship in equation (12-2). This equation shows the impact of changes in outputs of the constrained sectors in Region $1\left(Y_{C}^{1}\right)$ as well as the changes of injections from the ROW to the non-constrained sectors in both Regions 1 and 2 to the outputs of the non-constrained sectors in both Regions 1 and $2\left(Y_{N C}^{1}\right.$ and $\left.Y_{N C}^{2}\right)$ as well as the injection to Region 1.

$$
\begin{aligned}
d\left[\begin{array}{c}
Y_{N C}^{1} \\
X_{C}^{1} \\
Y_{N C}^{2}
\end{array}\right]= & {\left[\begin{array}{ccc}
-R^{11} & I & -R^{12} \\
\left(I-A_{N C}^{11}\right) & 0 & -A_{N C}^{12} \\
-A_{N C}^{21} & 0 & \left(I-A_{N C}^{22}\right)
\end{array}\right]^{-1} } \\
& {\left[\begin{array}{ccc}
-\left(I-A_{C}^{11}\right) & 0 & 0 \\
Q^{11} & I & 0 \\
Q^{21} & 0 & I
\end{array}\right] d\left[\begin{array}{c}
Y_{C}^{1} \\
X_{N C}^{1} \\
X_{N C}^{2}
\end{array}\right] }
\end{aligned}
$$


where $\left[\begin{array}{ccc}-R^{11} & I & -R^{12} \\ \left(I-A_{N C}^{11}\right) & 0 & -A_{N C}^{12} \\ -A_{N C}^{21} & 0 & \left(I-A_{N C}^{22}\right)\end{array}\right]^{-1}\left[\begin{array}{ccc}-\left(I-A_{C}^{11}\right) & 0 & 0 \\ Q^{11} & I & 0 \\ Q^{21} & 0 & I\end{array}\right]$ is

called inter-regional constrained fixed price multiplier (IR-CFPM). Analyzing the impact of a change in constrained outputs on the non-constrained outputs using this multiplier is called the IR-CFPM method.

This IR-CFPM method is utilized to simulate the impact of an increase in electricity demand in a country in East Asia with and without an electricity market integration for the region or only for Southeast Asia on socioeconomic and environmental conditions among Southeast Asian countries. Important to note is the assumptions adopted under this method. First, it is assumed that prices are fixed and therefore do not change in any simulation. Second, integrating the electricity market does not incur any technical or administrative costs to any country. Third, how much electricity that a country would supply to other country's electricity demand under electricity market integration is exogenously determined.

The second methodology is the household income microsimulation method linking macroeconomic indicators in the IRSAM to the incomes of several different household groups, such that several household microeconomic indicators, such as poverty incidence, can be estimated. In the computable general equilibrium (CGE) model literature, the household microsimulation method usually has been utilized to construct the top-down CGE approach, that is, linking results from a CGE model to household micro indicators (Bourguignon and Bussolo, 2013; Yusuf and Resosudarmo, 2015; Nurdianto and Resosudarmo, 2016). This chapter offers a novel household income microsimulation approach on how to link an IRSAM to household incomes for different category groups. The two principles adopted are as follows. First, the total payment of production activities to production factors should be equal to the total income of all institutions such as household, government, and firm. Second, it is assumed that the average propensities to consume are unchanged. Therefore, the value of any element in IRSAM at row $i$ and column $j$ can be obtained by multiplying a particular element of average propensity to consume matrix with a total value of the corresponding column. Therefore, given new total values of outputs after a simulation, this assumption allows us to compute new total income values for different types of production factors (labor and non-labor incomes) related to urban and rural households available in the IRSAM. After computing new values of labor and non-labor income and utilizing equation (12-3), we can define total incomes for different household percentile $c$ in urban or rural (ur) areas.

$$
H_{c}^{u r}=\sigma_{c}^{u r} s l^{u r} \sum_{v} \sum_{q} \frac{N_{c}^{q, v}}{\sum_{c} N_{c}^{q, v}} l b^{q, v}+\varsigma_{c}^{u r} s h^{u r} i n c_{-} s h_{c}^{u r} \sum_{w} \sum_{q} n l b^{q, w}
$$


Equation (12-3) can be explained as follows. In each Southeast Asian country, households are grouped into 100 household groups, based on percentile of their incomes from the poorest to the richest, in urban areas and another 100 household groups in rural areas (Nurdianto and Resosudarmo, 2016). The index $u r$ identifies whether a household group is in an urban or rural area. $H_{c}^{u r}$ donates the total income of households in percentile $c$ in the urban/rural areas.

Superscripts $q$ and $v$ denote production sectors in a region and labor types (skilled and unskilled labor). Term $N_{c}^{q, v}$ denotes the number of labor type $v$ by sector $q$ in household $c$. Therefore, term $\frac{N_{c}^{q, v}}{\sum_{c} N_{c}^{q, v}}$ is a sectoral labor share of household percentile $c$ in sector $q$.

Furthermore, $l b^{q, v}$ is the total labor income type $v$ in sector $q$ and $s l^{u r}$ is the share of total labor income of urban or rural households. Therefore, $\sigma_{c}^{u r} s l^{u r} \sum_{v} \sum_{q} \frac{N_{c}^{v, q}}{\sum_{c} N_{c}^{v, q}} l b^{v, q}$ is the total labor income of household group $c$ in $u r$ areas. Note that $\sigma_{c}^{u r}$ is a constant scaling factors to adjust the value of total labor income from the household survey data, where all parameters in equation (12-3) are estimated from, into IRSAM value.

Superscript $w$ denotes non-labor income types (land, natural resources, and capital). The term $n l b^{q, w}$ is non-labor income type $w$ in sector $q$, and $s h^{u r}$ is the share of total non-labor factor incomes for urban and rural households. Hence, $\zeta_{c}^{u r} s h^{u r} i n c_{-} s h_{c}^{u r} \sum_{w} \sum_{q} n l b^{q, w}$ is the total non-labor income of

household group $c$ in $u r$ areas. Note that $\zeta_{c}^{u r}$ a constant scaling factors to adjust the value of total non-labor income from the household survey data into IRSAM value.

After household income for all percentiles is computed in each Southeast Asian country, poverty incidence is estimated for both urban and rural areas following the method developed by Yusuf and Resosudarmo (2015). The third methodology is $\mathrm{CO}_{2}$ emission models for all Southeast Asian countries enabling calculation of sectoral emissions from these countries. Coefficients of sectoral emission per unit output are estimated for these models.

The general procedure in analyzing the impact of an electricity market integration of East Asia on Southeast Asian economies is as follows. First, using the IR-CFPM method, as stated in equation (12-2), we observe the macroeconomic impacts of any changes in the electricity sectors in a country to other sectors in that country and in other Southeast Asian countries - particularly on production sector (industrial) outputs and labor and non-labor incomes.

Information on changes in labor and non-labor incomes is then inserted into the household income microsimulation models for Southeast Asian countries, as given in equation (12-3). Also, the changes of production 
sectoral outputs are inserted into the $\mathrm{CO}_{2}$ emission models for Southeast Asian countries to predict the changes of total emission from the region.

\section{Data}

This chapter uses three datasets, namely, macro, micro, and $\mathrm{CO}_{2}$ emission datasets. The macro dataset is the GTAP 9 Data Base, which is a global database describing bilateral trade patterns, productions, consumptions, as well as intermediate use of commodities and services among and within countries in the world. The main source of GTAP 9 Data Base is inputoutput tables for countries around the world, which is then combined with trade and other required data to form a global inter-country input-output table. Hussein and Aguiar (2012) claim that GTAP Data Base covers approximately 120 countries, which constitute approximately $98 \%$ of global GDP. The dataset is for the year 2011 and in million USD.

To construct the East Asia IRSAM, this chapter extracts and converts the input-output tables in the GTAP 9 Data Base based on McDonald and Thierfelder (2004) to become an IRSAM covering six Southeast Asian countries (Indonesia, Malaysia, Singapore, Thailand, Vietnam, and the Philippines) and the rest of Southeast Asian countries (i.e., Brunei, Cambodia, East Timor, Laos, and Myanmar as a group) as well as Australia, China, India, Japan, and South Korea. This chapter then restructures the IRSAM, so that the new structure is closely following those of Round (1985) and Resosudarmo et al. (2009).

The main distinct features of the East Asia IRSAM compared to GTAP Data Base is as follows. The East Asia IRSAM disaggregates the regional household account in the original GTAP into rural and urban households as well as firm and government accounts. In the original GTAP, the regional household account receives all income in a country and allocates the income into private expenditure, government expenditure, and savingsinvestment (McDonald and Thierfelder, 2004; Delpiazzo and Standardi, 2014). The main disadvantage of the regional household account concept is that there is no explicit connection among household, government, and saving-investment account. Thus, it cannot be seen that household is saving as well as paying income tax (McDonald and Thierfelder, 2004). The disaggregation of regional household account following Nurdianto (2011) and Delpiazzo and Standardi (2014) allows for richer specifications, in particular, inter-institutional transfers in each region (McDonald and Sonmez, 2004).

In the East Asia IRSAM, inter-institutional transfers from the government to households are in the form of social expenditures by the government by taking a percentage of social expenditure to GDP of each country. Government revenue is set up as a certain percentage of GDP for each country implying that the government could have a surplus or deficit budget. This feature does not exist in the original GTAP Data Base. 


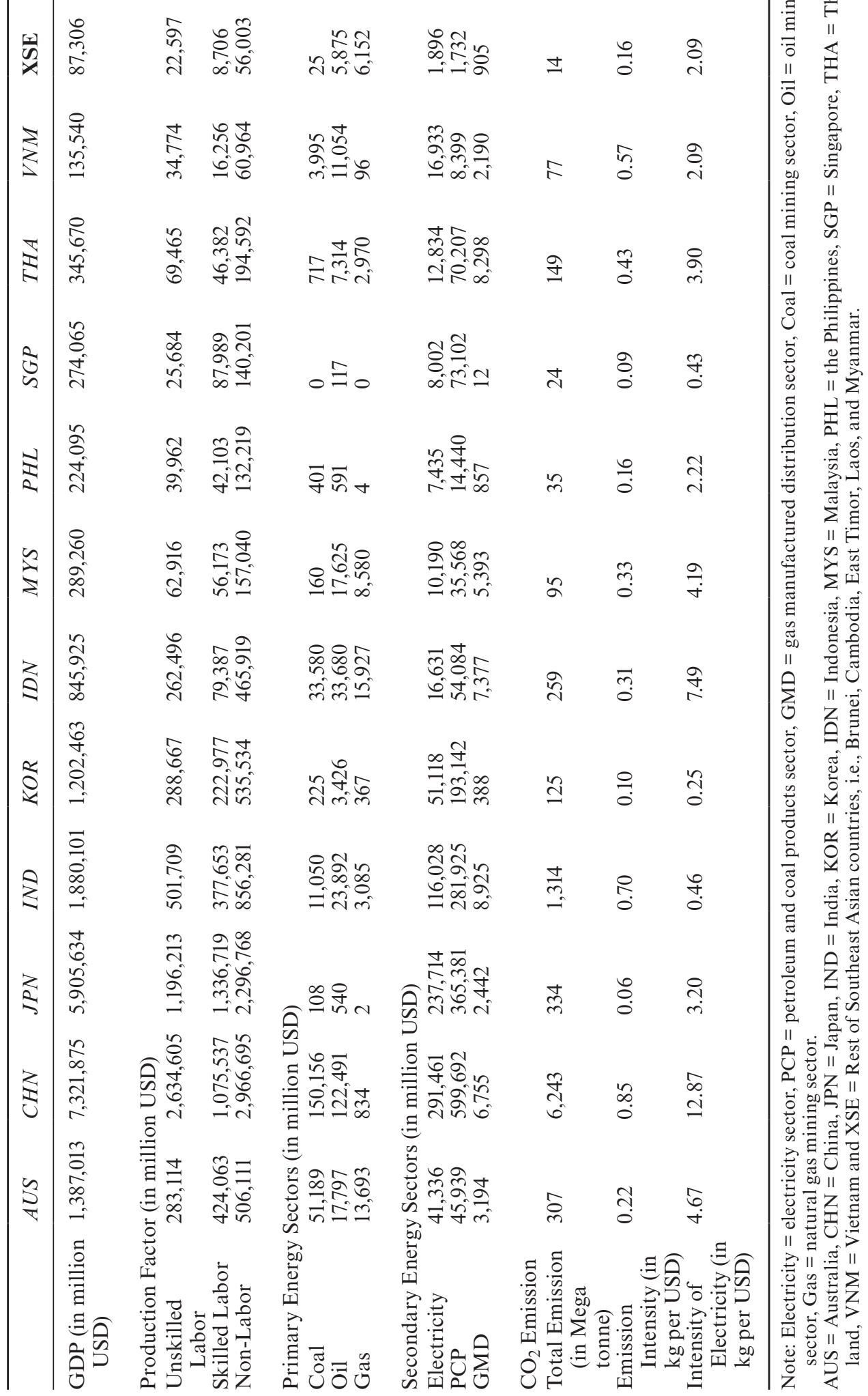


To develop household income microsimulation models, that is, to estimate coefficients in equation (12-3), this chapter utilizes several household survey data across ASEAN countries. For Indonesia, this chapter uses the 2011 National Socio-Economic Survey (SUSENAS); the 2014 Household Living Standards Survey (VHLSS) is used for Vietnam; a combination of the 2012 Family Income and Expenditure Survey (FIES) as well as the 2012 Labor Force Survey (LFS) is used for the Philippines; and, finally, for Thailand, this chapter extracts the dataset from the 2011 National Socio-Economic Survey (SES). Due to data limitations, the sectoral labor share, as well as the income share of Malaysia, is assumed to be similar to those in Thailand. This chapter does not conduct any analysis on poverty incidence in Singapore and the rest of Southeast Asian countries. Furthermore, for Singapore, it is expected that there is no poverty in the country.

Finally, for $\mathrm{CO}_{2}$ emission models, this chapter extracted $\mathrm{CO}_{2}$ emission data, in the million tonne $\mathrm{CO}_{2}$, by sector and by country available from the GTAP Data Base. For each sector, output- $\mathrm{CO}_{2}$ emission intensity coefficients are calculated. These coefficients are then used to calculate the new $\mathrm{CO}_{2}$ emission levels when there is a shock to the economy. Table 12.1 describes the selected macro and micro indicators of East Asian countries extracted from East Asia IRSAM and constructed from various survey data.

\section{Results}

In presenting the results, this chapter starts with describing macroeconomic impacts of an electricity market integration, in particular, changes in electricity and energy sectors, factor incomes, and GDP, on each Southeast Asian country (Tables 12.2 and 12.3). Then, it proceeds to show microeconomic impacts of an integrated electricity market on income distribution by percentile households and poverty incidence in each Southeast Asian country (Figures 12.3a-12.3d, 12.4a-12.4d, as well as Table 12.4). Finally, the consequences of an integrated electricity market on $\mathrm{CO}_{2}$ emissions by Southeast Asian countries are presented (Table 12.5).

\subsection{Macroeconomic impacts}

Table 12.2 shows the sectoral and factor income impacts of an integrated electricity market in East Asia. The first panel denotes simulation results for SIM1 under SIT2, where an increase in electricity demand in China is supplied by all East Asian countries because of the East Asia electricity market integration. The results indicate that the electricity market integration magnifies the leakage of electricity demand growth in China to all Southeast Asian countries' electricity sectors. For example, electricity sector outputs of Indonesia and Vietnam are higher by approximately $4.24 \%$ and $3.87 \%$, respectively, compared to the situation without any electricity 


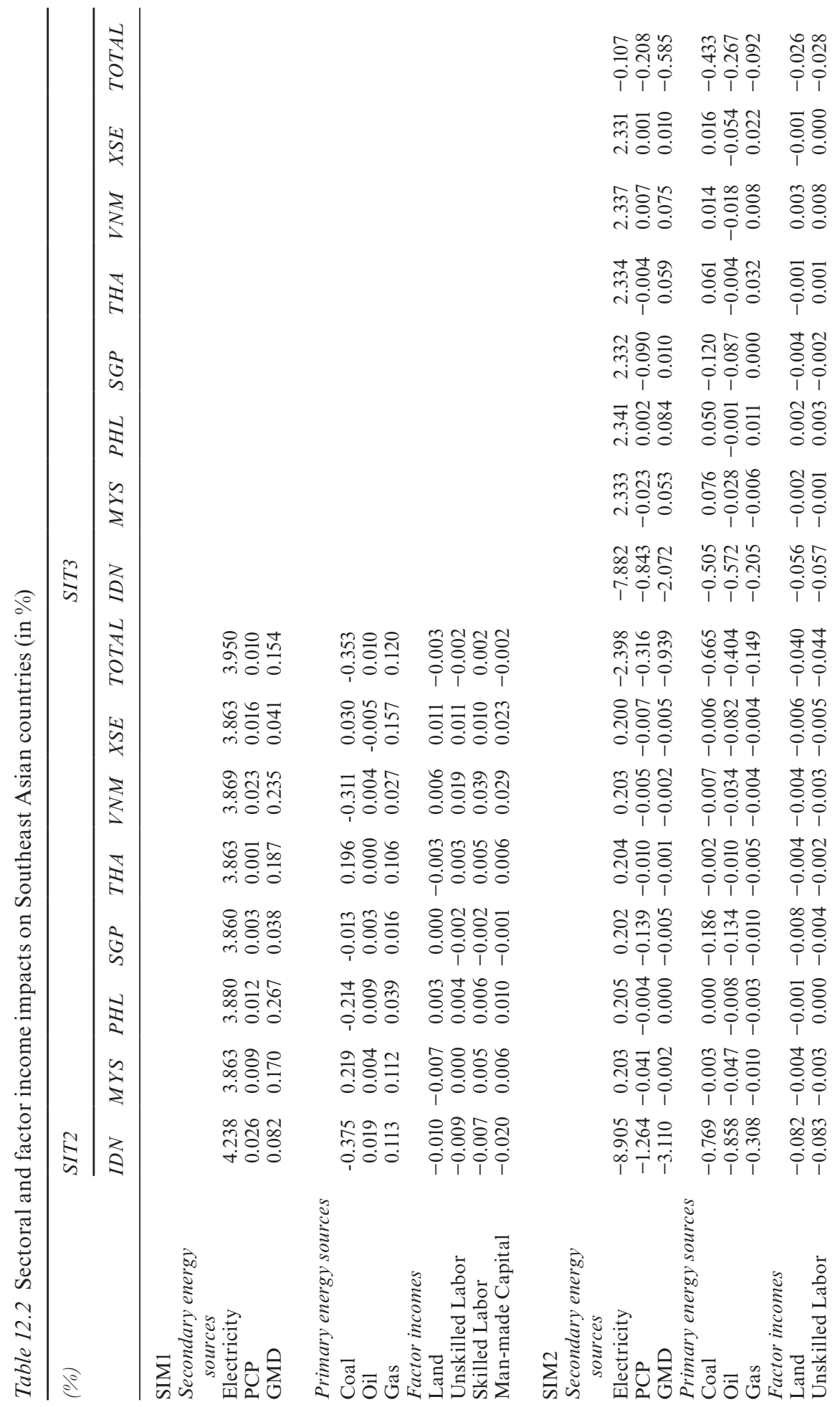


ตำ

ii

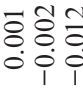

矛示官

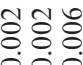

동ㅇํㅇํㅇ

i 1

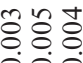

동휴응

ii

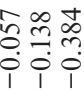

ปิํํำ

îi

ชิํㅡㅇํㅇ

i i

ชิㅇㅇ응

i 10

홍용

i i

ตํํ당

i i

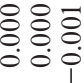

냥유.

ii

\&。ㅇำ

î

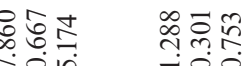

Tin

Ti

môे

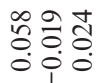

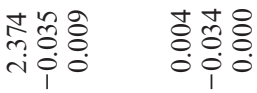

môे

유융ㅁํㅇ

흐용

i००

옹ํำ

항응

\&.?

政

Tij

근응

i

흘ํํำำ

o i i

응응

ii

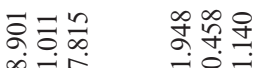

iTi Ti

ํㅟํํㅇ 응증

0 i i

i

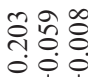

ฮิํํํㅡ.

i 10

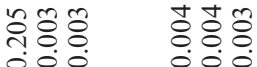

0 î

ii

ํํㅇㅎํ.

○i

颌吾

î

กิ?

官各吉

oil

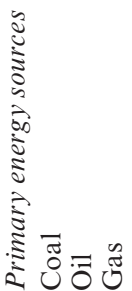

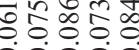

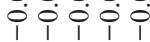

응형휴응

i 1 i i

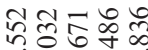

i†тi

형ㅎㅎㅇ응

i $\begin{aligned} & 1 \\ & 1\end{aligned}$

응용흐

i i i i i

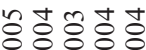

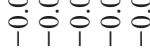

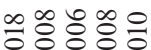

i 1 i 1 i

녕ㄴㅇㅇㅇ

i 0 i $\begin{array}{lll}0 & 0 & 0 \\ 0 & 1 & 1\end{array}$
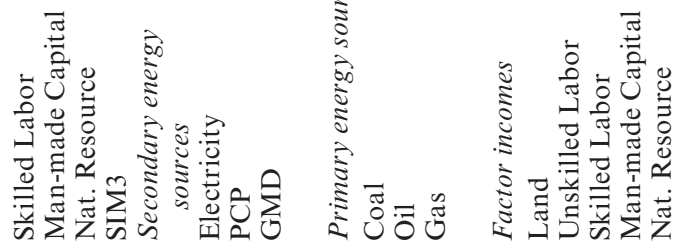

ت्ञ

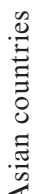

节

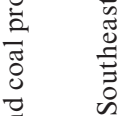

茨

$\stackrel{+}{0}$

II

崩

छ

苛

足

当 文

品 च

苛 司

荥 11

芯芯芯

के

峁 落

$\stackrel{\infty}{\Xi} \quad \Xi$

节

II की

$\overline{0} \quad$ के

苍

in

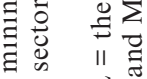

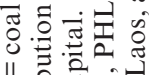

II

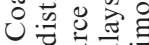

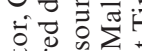

记范的

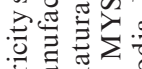

踏

를. 11 है

II

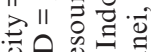

旅 $\|$

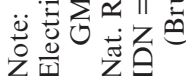


Table 12.3 Changes in Southeast Asian countries' gross domestic product changes (in $\%$ )

\begin{tabular}{lrrrrrrrr}
\hline$(\%)$ & IDN & MYS & PHL & SGP & THA & VNM & XSE & TOTAL \\
\hline SIM1 & & & & & & & & \\
SIT2 & -0.017 & 0.005 & 0.008 & -0.002 & 0.005 & 0.022 & 0.018 & -0.003 \\
SIM2 & & & & & & & & \\
SIT2 & -0.157 & -0.006 & 0.000 & -0.004 & -0.002 & -0.004 & -0.009 & -0.064 \\
SIT3 & -0.109 & -0.002 & 0.004 & -0.002 & 0.002 & 0.009 & -0.002 & -0.042 \\
SIM3 & & & & & & & & \\
SIT2 & -0.004 & -0.008 & -0.004 & -0.006 & -0.010 & -1.253 & -0.012 & -0.099 \\
SIT3 & -0.001 & -0.003 & 0.002 & -0.003 & -0.003 & -0.826 & -0.003 & -0.063 \\
\hline
\end{tabular}

Note: IDN = Indonesia, MYS = Malaysia, $\mathrm{PHL}=$ the Philippines, $\mathrm{SGP}=$ Singapore, $\mathrm{THA}=$ Thailand, VNM = Vietnam, XSE $=$ Rest of Southeast Asian countries (Brunei, Cambodia, East Timor, Laos, and Myanmar) and TOTAL = total Southeast Asia.

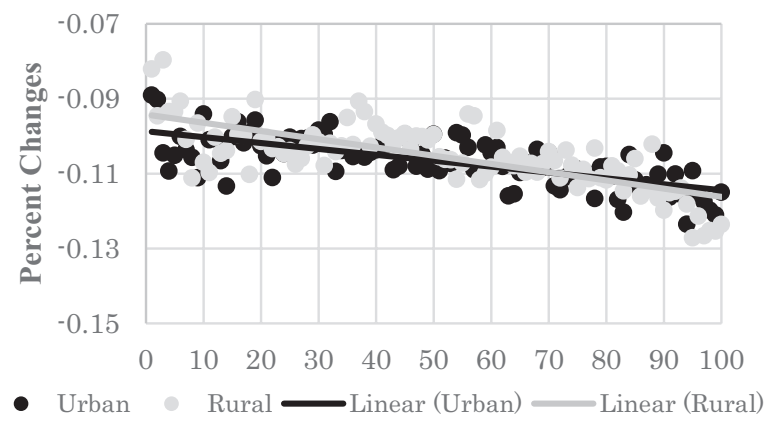

Figure 12.3a Percentage income changes of income percentile household groups in Indonesia under SIM2-SIT2.

Note: Horizontal axis lists income percentile household groups from the poorest to the richest.

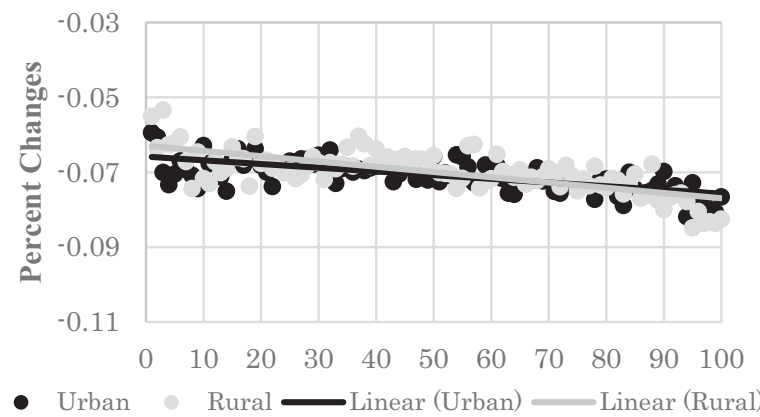

Figure 12.3b Percentage income changes of income percentile household groups in Indonesia under SIM2-SIT3.

Note: Horizontal axis lists income percentile household groups from the poorest to the richest. 


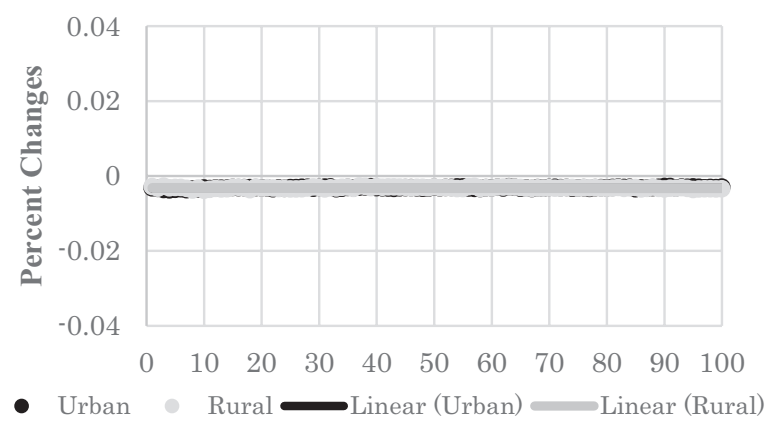

Figure $12.3 c$ Percentage income changes of income percentile household groups in Indonesia under SIM3-SIT2.

Note: Horizontal axis lists income percentile household groups from the poorest to the richest.

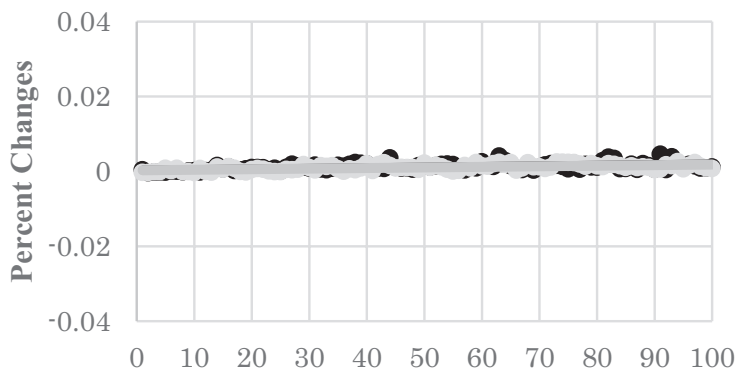

- Urban Rural Linear (Urban) Linear (Rural)

Figure 12.3d Percentage income changes of income percentile household groups in Indonesia under SIM3-SIT3.

Note: Horizontal axis lists income percentile household groups from the poorest to the richest.

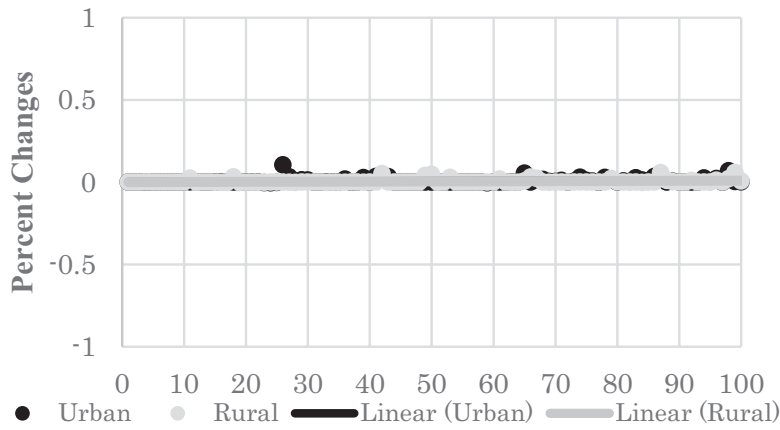

Figure 12.4a Percentage income changes of income percentile household groups in Vietnam under SIM2-SIT2.

Note: Horizontal axis lists income percentile household groups from the poorest to the richest. 


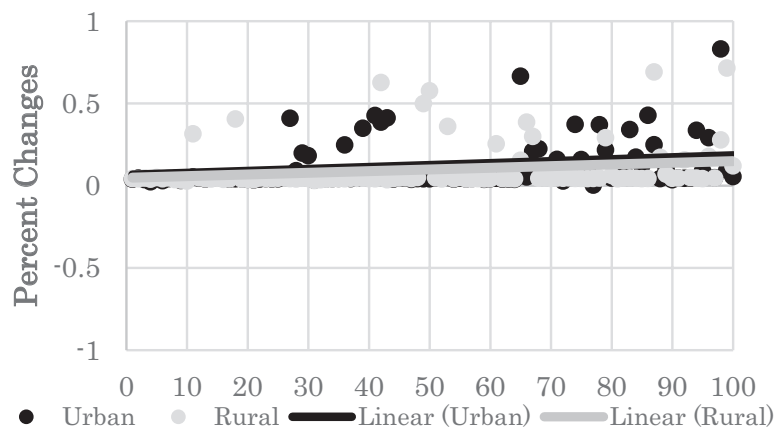

Figure 12.4b Percentage income changes of income percentile household groups in Vietnam under SIM2-SIT3.

Note: Horizontal axis lists income percentile household groups from the poorest to the richest.

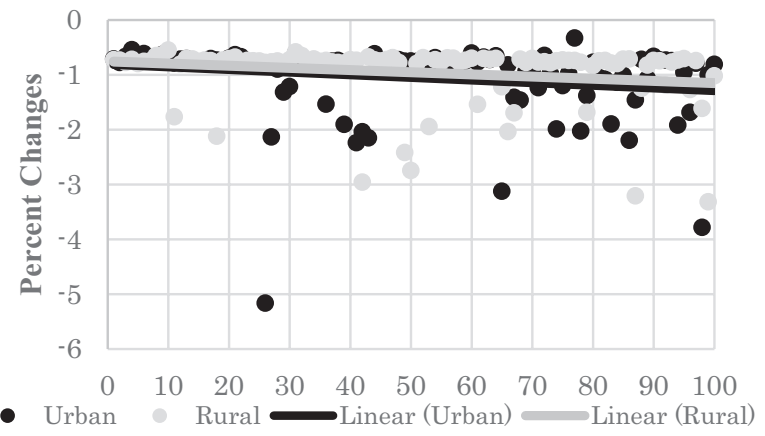

Figure $12.4 \mathrm{c}$ Percentage income changes of income percentile household groups in Vietnam under SIM3-SIT2.

Note: Horizontal axis lists income percentile household groups from the poorest to the richest.

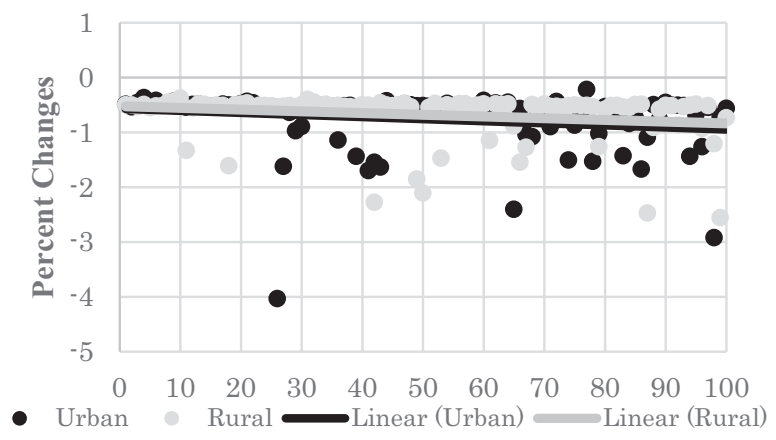

Figure 12.4d Percentage income changes of income percentile household groups in Vietnam under SIM3-SIT3.

Note: Horizontal axis lists income percentile household groups from the poorest to the richest. 
Table 12.4 Changes in percentage of poverty incidence

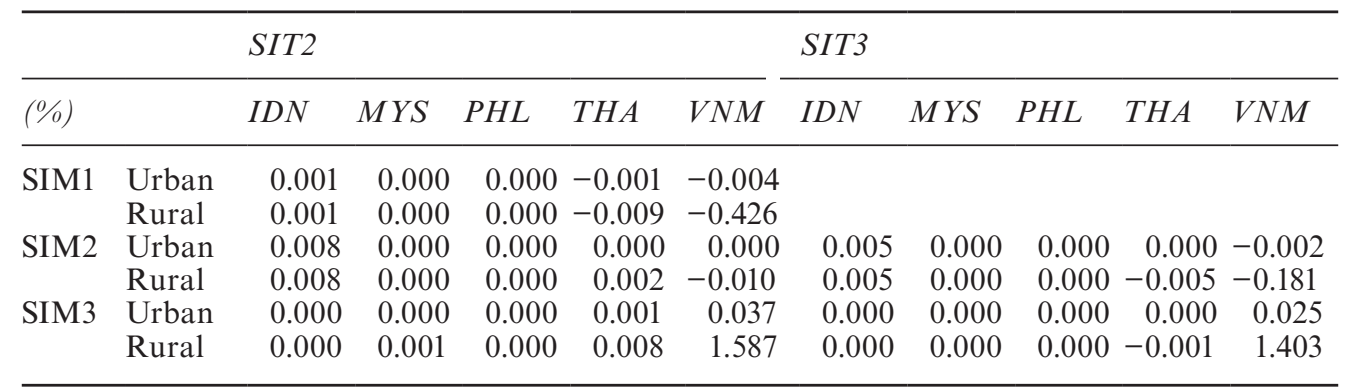

Note: IDN $=$ Indonesia, MYS $=$ Malaysia, PHL $=$ the Philippines, SGP $=$ Singapore, THA $=$ Thailand, VNM $=$ Vietnam and XSE $=$ Rest of Southeast Asian countries (Brunei, Cambodia, East Timor, Laos, and Myanmar).

Table 12.5 Changes in $\mathrm{CO}_{2}$ emissions (in percentage change)

\begin{tabular}{lcccccccc}
\hline$\%)$ & $I D N$ & MYS & PHL & SGP & THA & VNM & XSE & TOTAL \\
\hline SIM1 & & & & & & & & \\
SIT2 & 2.042 & 1.747 & 1.835 & 0.561 & 1.315 & 1.788 & 1.350 & 1.724 \\
SIM2 & & & & & & & & \\
SIT2 & -4.734 & 0.084 & 0.097 & 0.026 & 0.067 & 0.093 & 0.064 & -1.892 \\
SIT3 & -4.136 & 1.050 & 1.107 & 0.338 & 0.790 & 1.080 & 0.807 & -1.155 \\
SIM3 & & & & & & & & \\
SIT2 & 0.097 & 0.088 & 0.095 & 0.025 & 0.061 & -4.456 & 0.053 & -0.476 \\
SIT3 & 1.143 & 1.072 & 1.126 & 0.344 & 0.800 & -3.904 & 0.815 & 0.397 \\
\hline
\end{tabular}

Note: IDN = Indonesia, MYS $=$ Malaysia, PHL $=$ the Philippines, SGP $=$ Singapore, THA = Thailand, $\mathrm{VNM}=$ Vietnam, $\mathrm{XSE}=$ Rest of Southeast Asian countries $($ Brunei, Cambodia, East Timor, Laos, and Myanmar) and TOTAL = total Southeast Asia.

market integration in East Asia when the electricity demand in China increases by $10 \%$.

An important result is lower outputs of coal and oil sectors in several Southeast Asian countries, such as in Indonesia, the Philippines, and Vietnam. This means that the opportunity to supply China with electricity could lower the countries' increase in exports of coal and oil to China in response to an increase in electricity demand in China. This situation, nevertheless, could potentially induce a higher level of $\mathrm{CO}_{2}$ emissions from Southeast Asia, that is, $\mathrm{CO}_{2}$ emission leakages from China to Southeast Asia.

Changes in electricity and energy outputs are then transmitted to changes in overall sectoral outputs and, finally to, factor incomes. Table 12.2 shows that in SIM1, the East Asia electricity market integration is mostly beneficial for skilled labor in Southeast Asia, except for those in Indonesia and Singapore. For unskilled labor and non-labor, the East Asia electricity market integration, in general, has lower benefits of an increasing electricity 
demand in China. Indonesia deserves particular attention because all factor incomes under an electricity market integration are lower than those without this integration. This indicates that it is more beneficial for Indonesia to export coal than electricity in responding to an increase in Chinese electricity demand. In general, in Indonesia, primary energy sectors create higher value-added (mostly rents to natural resource, land, and man-made capital) than the secondary energy sectors.

The next two panels in Table 12.2 show results of SIM2 and SIM3. These two simulations assume increasing electricity sector output values in Indonesia and Vietnam. Both countries have a relatively similar value of electricity outputs as indicated in Table 12.1. Therefore, the shocks are relatively comparable in terms of magnitude.

In the absence of electricity market integration, an increase in electricity demand in a country would be beneficial, in terms of having higher outputs of its electricity/energy sectors and higher factor incomes. An integrated electricity market in East Asia, or in Southeast Asia only, shares (or leaks) this benefit with other members where their electricity sectors are integrated. Therefore, electricity/energy outputs and factor incomes of the country where the increase in electricity occurs would not increase as high as when there is no electricity market integration.

As shown in Table 12.2 under SIM 2, the changes of electricity/energy outputs and factor incomes in Indonesia under electricity market integration situations (SIT2 or SIT3) are lower than those without electricity market integration (SIT1). A similar situation occurs in Vietnam under SIM3. It is therefore expected that the energy sectors and hence factor incomes of the country where the increase in electricity demand occurs would have a lower increase under an electricity market integration than under no electricity market integration.

For other countries receiving the spillover, it is difficult to determine what happens to them, that is, the sectoral and factor income dynamics are not straightforward to be described. For example, under SIM2, except for the Philippines, it seems more beneficial for Malaysia, Singapore, Thailand, Vietnam, and the rest of Southeast Asian countries to respond to the increase in electricity demand in Indonesia by supplying Indonesia with other goods and services than electricity. Almost all factor incomes in those countries have a lower growth under electricity market integration compared to without electricity market integration. A relatively similar situation occurs under SIM3.

Further examination of SIM2 and SIM3 shows that their impacts on energy sectors in Indonesia and Vietnam are different. Indonesia's electricity imports restrict growth of the country's crude oil (Oil) and coal outputs, while Vietnam's electricity imports restrict growth of the country's coal and natural gas. This difference in Indonesia and Vietnam is mainly because of the different energy sources for the countries' electricity sectors. Indonesia mostly uses oil and coal, while Vietnam mostly uses coal and natural gas. 
Changes in factor incomes caused by the shocks in SIM1, SIM2, and SIM3 translate into changes in GDP for each country in the model (Table 12.3). These results highlight some possible answers to the following issue. Electricity market integration in East Asia is meant to increase electricity security in the region, because an increase in electricity demand in one country would also be supplied by other countries in the region. However, whether it could also serve as a potential channel leaking a positive shock in a country to others within the electricity market integration is less understood.

Table 12.3 shows that China's electricity growth under the East Asia electricity market integration is more likely to reduce the growth of total GDP of Southeast Asia compared to a situation without an electricity market integration (SIM1). Indonesia and Singapore would experience lower GDP, despite higher GDP in other Southeast Asian countries. In other words, an increase in electricity demand in China does leak to Southeast Asia inducing higher GDP growth for most Southeast Asian countries, because they now have an opportunity to supply China with their electricity, except Indonesia and Singapore.

When the increase in electricity demand is within Southeast Asian countries (SIM2 and SIM3), the GDP of almost all Southeast Asian countries' is higher without the existence of an electricity market integration. The existing trade structure within East Asia seems to be already in an optimal situation for most Southeast Asian countries. Shifting trade patterns within East Asia toward more electricity trades does not likely produce higher GDP among Southeast Asian countries.

When electricity market integration occurs only in Southeast Asia (SIT3), or the Southeast Asia electricity market integration, some countries could actually have higher GDP. The Philippines, for example, seems to be better off (i.e., having higher GDP) with the Southeast Asia electricity market integration when there is an increase in electricity demand either in Indonesia or in Vietnam. Thailand and Vietnam, as another example, seem to be better off when there is an increase in electricity demand in Indonesia under the Southeast Asia electricity market integration.

\subsection{Distributional impacts}

Table 12.4 presents how changes in rates of poverty incidence would be different between a situation with an electricity market integration and one without. In general, changes in rates of poverty incidence in Southeast Asian countries would be similar in both situations. When there is an increase in electricity demand in China (SIM1), rates of poverty incidence tend to be higher in Indonesia, Malaysia, and the Philippines under the existence of the East Asia electricity market integration than those when there is no electricity market integration. The opposite situation exists for Thailand and Vietnam. 
When there is an increase in electricity demand in the Southeast Asian region, levels of poverty in the region in general are higher under an electricity market integration than those under no electricity market integration. Only a few cases under electricity market integration produce a lower poverty level. For example, the Southeast Asia electricity market integration would only lower poverty levels in Vietnam when there is an increase in electricity demand in Indonesia.

In terms of income distributional impacts of electricity market integration among household (in percentile) groups, the general pattern is as follows. The distributional impact of an electricity market integration tends be progressive; that is, the incomes of the rich would be more affected under an electricity market integration than those of the poor, in the country where electricity demand increases, in comparison to a situation where there is no electricity market integration. When the increase in electricity demand is in another member of the integration, the distributional impact of having an electricity market integration tends to be relatively flat among household groups. For example, in the case of Indonesia, progressive impacts seem to occur under an electricity market integration, when there is an increase in electricity demand in the country (Figures 12.3a and 12.3b). When the increase in electricity demand is in another country of the integration, the distributional income impact is relatively flat or slightly regressive (Figures $12.3 \mathrm{c}$ and 12.3d). A similar situation occurs in Vietnam: It is progressive in SIM3 (Figures 12.4c and 12.4d) and it is slightly regressive in SIM2 (Figures 12.4a and 12.4b).

The main reason for this could be because energy sectors tend to be manmade capital, land, and natural resource-intensive industries, and therefore most factor incomes go to owners of this capital, that is, richer household groups. Hence, energy sectors under electricity market integration could grow in response to an increase in electricity demand in the country in comparison to when there is no electricity market integration, and this situation affects richer household groups more than poorer household ones.

\subsection{Environmental impacts}

The impact of electricity market integration on $\mathrm{CO}_{2}$ emissions in Southeast Asia is shown in Table 12.5. A growing electricity demand in China (SIM1) under the East Asia electricity market integration (SIT2) induces higher total $\mathrm{CO}_{2}$ emissions from Southeast Asia; that is, creating $\mathrm{CO}_{2}$ emission leakage from China to Southeast Asia. $\mathrm{CO}_{2}$ emission leakage to the Southeast Asia region is because of the increase in electricity productions by Southeast Asian countries. ${ }^{8}$

Conversely, a growing electricity demand in Indonesia (SIM2) lowers the total $\mathrm{CO}_{2}$ emissions from Southeast Asia under an electricity integrated market. This is because electricity market integration switches electricity supplies from $\mathrm{CO}_{2}$-intensive Indonesia's electricity to other East Asian countries with less $\mathrm{CO}_{2}$-intensive electricity sectors (Table 12.1). 
A growth in electricity demand in Vietnam (SIM3) induces a lower total $\mathrm{CO}_{2}$ emission from Southeast Asia under the East Asia electricity market integration (SIT2). This electricity growth induces a shift in electricity supply from Vietnam to East Asian countries whose electricity sector is less $\mathrm{CO}_{2}$ intensive than Vietnam's. However, a growth in electricity demand in Vietnam under the Southeast Asia electricity market integration (SIT3) produces a higher total $\mathrm{CO}_{2}$ emission from Southeast Asia. In Southeast Asia, many countries have more $\mathrm{CO}_{2}$-intensive electricity sectors compared with Vietnam.

It can be concluded that the Southeast Asia electricity market integration would not reduce $\mathrm{CO}_{2}$ emissions in Southeast Asia if the countries where electricity demands increase are having a cleaner electricity sector.

\section{Conclusions}

This chapter has aimed to analyze the inter-regional socioeconomic and environmental impacts of an integrated electricity market on Southeast Asian countries. An integrated electricity market has been considered an important measure to improve energy security in the region. However, the socioeconomic and environmental consequences have been less understood. To achieve this goal, this chapter utilizes an East Asia IRSAM. First, an inter-regional CFPM method is implemented at the East Asia IRSAM to simulate the macroeconomic impacts of an integrated electricity market integration in East Asia. Second, this chapter uses a household income microsimulation method to translate the macroeconomic impacts of an integrated electricity market into changes in incomes of various household groups (by income percentiles). These income changes allow us to observe the impact of an electricity market integration in East Asia on rates of poverty incidence in Southeast Asian countries. Third, a $\mathrm{CO}_{2}$ emission model is developed to predict $\mathrm{CO}_{2}$ emissions from Southeast Asian countries' production sectors.

This chapter analyzes the impact of an increase in electricity demand in a country in East Asia with and without an electricity market integration for the region (i.e., the East Asia electricity market integration) or only for Southeast Asia (i.e., the Southeast Asia electricity market integration) on socioeconomic and environmental conditions among Southeast Asian countries. Comparing simulation results with and without an electricity market integration shows the impacts of this integration on Southeast Asian countries.

Based on the analysis of this chapter, we draw the following conclusions. First, an electricity market integration, in general, does not obviously provide economic benefits, that is, positive economic leakages, for Southeast Asian countries. When there is an increase in electricity demand in a country outside Southeast Asia, all Southeast Asian countries, except Indonesia and Singapore, benefit from an electricity market 
integration in East Asia region. Their GDP under an electricity market integration would be higher than those under no electricity market integration. An increase in electricity demand in Indonesia and Vietnam (i.e., a country within Southeast Asia) reduces GDP growth in most Southeast Asian countries under an electricity market integration. In this case, only the Philippines might have a higher GDP under an electricity market integration.

Second, in most cases, an electricity market integration in East Asia, or in Southeast Asia only, produces higher rates of poverty incidence in most Southeast Asian countries than no electricity market integration does. The main reason for this is that electricity market integration restructures the economy of each country such that most factor incomes would be lower than those under no electricity market integration.

Third, in most cases, distributional household income impact of an electricity market integration in East Asia would most likely be progressive. Energy sectors, which are mostly affected by electricity market integration, are capital intensive and mostly owned by richer households.

Finally, electricity market integration in East Asia tends to increase $\mathrm{CO}_{2}$ emissions from Southeast Asia, creating $\mathrm{CO}_{2}$ emission leakage and relocation. Any increase in electricity demand from outside Southeast Asia increases electricity productions in Southeast Asia, inducing $\mathrm{CO}_{2}$ emission leakage and relocation from outside Southeast Asia (mainly China) to Southeast Asia. Only when the increase in electricity demand comes from a Southeast Asian country with a high $\mathrm{CO}_{2}$ intensity electricity sector, such as Indonesia, $\mathrm{CO}_{2}$ emissions from Southeast Asia would be lower under an electricity market integration.

It is important to understand the drawbacks of the assumptions adopted in this chapter. First, it is assumed that prices are fixed and therefore do not change in any simulation. Electricity prices would most likely be lower under electricity market integration. The results in this chapter, hence, underestimate the impact of electricity market integration on the economy and $\mathrm{CO}_{2}$ emission leakages and relocation.

Second, integrating the electricity market does not incur any technical or administrative costs to any country. Electricity market integration would most likely induce some technical or administrative costs. The results in this chapter, hence, could overestimate the impact of electricity market integration on the economy and $\mathrm{CO}_{2}$ emission leakages and relocation. Finally, under electricity market integration, any increasing demand will be supplied by all country members of the integration, proportionate to their total electricity output. This situation may not be true.

This chapter certainly could enrich debates on whether an electricity market integration, besides improving energy security, would induce economic and environmental benefits in the region. However, further research overcoming the shortcomings in the chapter is warranted to provide more definite solutions to this issue. 


\section{Notes}

1 See also: https://www.nordpoolgroup.com

2 The Association of Southeast Asian Nations (ASEAN) is a regional intergovernmental organization comprising ten countries in Southeast Asia, which promotes intergovernmental cooperation and facilitates economic, political, security, military, educational, and sociocultural integration among its members and other countries in Asia. Members of ASEAN are Singapore, Brunei, Malaysia, Thailand, the Philippines, Indonesia, Vietnam, Laos, Myanmar, and Cambodia.

3 China is chosen to represent a case in which the increase in electricity demand is in a country within East Asia but outside Southeast Asia. The impact on Southeast Asia of this case would most likely be similar than if the increase is in other East Asia outside Southeast Asia. The $10 \%$ is to represent a marginal change case.

4 Indonesia and Vietnam are the two countries in Southeast Asia where electricity demands have been fast increasing in the past three decades. Furthermore, their energy sector compositions are very different.

5 For SIM1, SIT3 will be the same as SIT1.

6 The inter-regional CFPM approach is relatively different from standard IRSAM multiplier. The explanation and derivation of standard IRSAM multiplier, for example, can be found in Resosudarmo et al. (2009).

7 The details of constructing East Asia IRSAM are available upon request to the author.

8 Even though China's electricity sector is more $\mathrm{CO}_{2}$-intensive than those in other East Asian countries (Table 12.1), note that total emissions in East Asia are actually lower under East Asia electricity market integration (not presented in this chapter).

\section{References}

Barbosa, L.de S.N.S., Bogdanov, D., Vainikka, P. and Breyer, C. (2017). Hydro, wind and solar power as a base for a $100 \%$ renewable energy supply for South and Central America, PLoS One 12(3), 1-28, https://doi.org/10.1371/journal. pone.0173820.

Bourguignon, F. and Bussolo, M. (2013). Income distribution in computable general equilibrium modeling, in P.B. Dixon and D.W. Jorgenson (eds.), Handbook of Computable General Equilibrium Modeling Vol. 1, Oxford: Elsevier, 1383-1437.

Dahlke, S. (2020). Integrating electricity markets: Impacts of increasing trade on prices and emissions in the western United States, International Journal of Sustainable Energy Planning and Management 25, 45-60.

Delpiazzo, E. and Standardi, G. (2014). Introducing an explicit government institution in ICES model, Climate Impacts and Policy Division Research Papers Issue RP0243, Centro Euro-Medirerraneo sui Cambiamenti Climatici.

Denholm, P., King, J.C., Kutcher, C.F., and Wilson, P.P.H. (2012). Decarbonizing the electric sector: Combining renewable and nuclear energy using thermal storage, Energy Policy 44, 301-311.

ERIA, (2014). Investing in power grid interconnection in East Asia, ERIA Research Project Report 2013, No. 26, Economic Research Institute for ASEAN and East Asia.

Garnaut, R. (2019). Super-Power: Australia's Low-Carbon Opportunity, Melbourne: La Trobe University Press.

Glachant, J.M. (2010). The achievement of the EU electricity internal market through market coupling, EUI Working Papers RSCAS 2010/87, Robert Schuman Centre for Advanced Studies, Florence School of Regulation. 
Hartono, D. and Resosudarmo, B.P. (2008). The economy-wide impact of controlling energy consumption in Indonesia: An analysis using a Social Accounting Matrix framework, Energy Policy 36(4), 1404-1419.

Hussein, Z. and Aguiar, A.H. (2012). Macroeconomic data, in B. Narayanan G., A. Aquiar and R. McDougall (eds.), Global Trade, Assistance, and Production: The GTAP 8 Data Base, Indiana: Center for Global Trade Analysis, Purdue University, $47-58$.

International Energy Agency. (2018). World Energy Outlook 2018, International Energy Agency, https://doi.org/10.1787/weo-2018-en.

Lilliestama, J., Barradi, T, Caldés, N., Gomez, M., Hanger, S., Kern, J., Komendantova, N., Mehos, M., Hong, W.M., Wang, Z., and Patt, A. (2018). Policies to keep and expand the option of concentrating solar power for dispatchable renewable electricity, Energy Policy 116, 193-197.

McDonald, S. and Sonmez, Y. (2004). Augmenting the GTAP Database with Data on Inter-Regional Transactions, Sheffield Economic Research Paper Series 2004009, Department of Economics, University of Sheffield.

McDonald, S., and Thierfelder, K. (2004). Deriving a global social accounting matrix from GTAP versions 5 and 6 data, GTAP Technical Paper No. 22, Purdue University.

Newbery, D., Strbac, G. and Viehoff, I. (2016). The benefits of integrating European electricity markets, Energy Policy 94, 253-263.

Nurdianto, D.A. and Resosudarmo, B.P. (2016). Economy-wide impact of a carbon tax in ASEAN, Journal of Southeast Asian Economics 33(1), 1-15.

Resosudarmo, B.P., Nurdianto, D.A. and Hartono, D. (2009). The Indonesian InterRegional Social Accounting Matrix for fiscal decentralisation analysis, Journal of Indonesian Economy and Business 24(2), 145-162.

Resosudarmo, B.P., Nurdianto, D.A. and Effendi, Y. (2021), Energy insecurity in the ASEAN region: The Implications of energy policy reform, Singapore Economic Review 68(2), 345-368, https://doi.org/10.1142/S0217590820430079.

Resosudarmo, B.P. and Thorbecke, E. (1996). The impact of environmental policies on household incomes for different socio-economic classes: The case of air pollutants in Indonesia, Ecological Economics 17(2), 83-94.

Resosudarmo, B.P. and Thorbecke, E. (1998). Reducing the number of pesticide related illnesses: The impact on household in Indonesia, Bulletin of Indonesian Economic Studies 34(2), 143-157.

Round, J.I. (1985). Decomposing multipliers for economic systems involving regional and world trade, The Economic Journal 95: 378, 383-399.

Shi, X. and Kimura, F. (2010). Energy market integration in the East Asia summit region: Review of initiatives and estimation of benefits, ERIA Research Project Report 2009, No. 13, Economic Research Institute for ASEAN and East Asia.

Wolfram, C., Shelef, O. and Gertler, P. (2012). How will energy demand develop in the developing world? Journal of Economic Perspectives 26(1), 119-138.

Wu, Y., Kimura, F. and Shi, X. (2013). Energy market integration in East Asia: Deepening understanding and moving forward, in Y. Wu, F. Kimura and X. Shi (eds.), Energy Market Integration in East Asia: Deepening Understanding and Moving Forward, Oxon: Routledge, 1-201.

Yusuf, A.A. and Resosudarmo, B.P. (2015). On the distributional impact of a carbon tax in developing countries: The case of Indonesia, Environmental Economics and Policy Studies 17(1), 131-156. 